\title{
CLINICO-EPIDEMIOLOGICAL STUDY OF CHILDHOOD VITILIGO
}

\begin{abstract}
S. Jhansi Lakshmi 1 , M. Parvathi², Shaik Asha ${ }^{3}$, Suneetha Rani Patro ${ }^{4}$, Ch. Naveen Kumar ${ }^{5}$, Swetha Naidu K6, Chandrasekhar Nallabolu, S. S. N. Chakravarthy ${ }^{8}$
\end{abstract}

${ }^{1}$ Assistant Professor, Department of DVL, King George Hospital, Visakhapatnam. ${ }^{2}$ Assistant Professor, Department of DVL, King George Hospital, Visakhapatnam. 3Postgraduate Student, Department of DVL, King George Hospital, Visakhapatnam. ${ }^{4}$ Postgraduate Student, Department of DVL, King George Hospital, Visakhapatnam. 5Postgraduate Student, Department of DVL, King George Hospital, Visakhapatnam. ${ }^{6}$ Postgraduate Student, Department of DVL, King George Hospital, Visakhapatnam. ${ }^{7}$ Postgraduate Student, Department of DVL, King George Hospital, Visakhapatnam. 8Postgraduate Student, Department of DVL, King George Hospital, Visakhapatnam.

ABSTRACT

\section{BACKGROUND}

Vitiligo is a disorder of melanocytes characterised by depigmentation and is a psychologically devastating disorder. Childhood vitiligo has different epidemiological clinical characteristics that manifests as circumscribed achromic macules often associated with leukotrichia and histologically by degeneration and disappearance of melanocytes in the involved skin and not infrequently in the pigment epithelium of the eyes, leptomeninges and inner ear. Vitiligo can develop at any age and most commonly affects the skin phototypes III and IV. It affects different races, religions and socioeconomic groups and different dietary habits do not show any significant variation in proclivity towards the disease.(1)

\section{MATERIALS AND METHODS}

30 patients of childhood vitiligo of age less than 18 years attending the DVL Department of KGH, Visakapatnam, between the months of August 2015 to January 2016 were selected.

Objectives of the Study- To study clinical and epidemiological characteristics of childhood vitiligo and to see the association of vitiligo with other autoimmune disorders.

Study Design- It is a descriptive study.

Study Setting- Department of DVL, Andhra Medical College, King George Hospital, Visakhapatnam.

\section{RESULTS}

Out of 30 patients, vitiligo vulgaris was the most common type of vitiligo seen in $40 \%$ of children followed by each $20 \%$ focal and segmental vitiligo and acrofacial vitiligo constitutes another $20 \%$.

\section{CONCLUSION}

Vitiligo is a common depigmentary disorder. Vitiligo vulgaris is being the most common pattern and lower limbs being the most common site in paediatric age group. Autoimmune disease associations were more frequent in non-segmental vitiligo. Among the cutaneous associations, atopic dermatitis and family history of few autoimmune diseases were noted.

\section{KEYWORDS}

Depigmentation, Clinico-Epidemiological Study, Autoimmune.

HOW TO CITE THIS ARTICLE: Lakshmi SJ, Parvathi M, Asha S, et al. Clinico-epidemiological study of childhood vitiligo. J. Evolution Med. Dent. Sci. 2018;7(06):794-796, DOI: 10.14260/jemds/2018/180

\section{BACKGROUND}

Vitiligo is an acquired hypomelanotic disorder of skin characterised by idiopathic, progressive, circumscribed hypomelanosis of the skin and hair with total absence of melanocytes. It is a psychologically devastating, cosmetically disfiguring disease and resistant to therapy. Hence, this study was undertaken to understand the epidemiological and clinical presentation of vitiligo in children.

'Financial or Other Competing Interest': None.

Submission 12-07-2017, Peer Review 21-01-2018,

Acceptance 29-01-2018, Published 05-02-2018.

Corresponding Author:

Dr. M. Parvathi,

D. No. 7-5-92, Plot No. 54

Panduranga Puram,

Visakhapatnam-530003.

E-mail: parvathi2448@gmail.com

DOI: $10.14260 /$ jemds $/ 2018 / 180$

\section{(c) $(1) \risingdotseq$}

\section{MATERIALS AND METHODS}

A retrospective study was done after taking a complete history including age, sex, duration of the disease, family history, h/o Koebner phenomenon, h/o associated autoimmune disorder were elucidated and noted. All the patients were thoroughly examined and the following data like sites of area of involvement, leukotrichia and pattern of vitiligo was noted.

Patients were classified into 2 groups, localised (Focal, Segmental and Mucosal) and Generalised (Vitiligo vulgaris, Acrofacial vitiligo and Vitiligo universalis).(2) Focal vitiligo is defined as a single or few lesions localised to one body part. Segmental vitiligo is characterised by the presence of depigmenting macules arranged unilaterally. Mucosal vitiligo is defined as unique involvement of oral or genital mucosa. Vitiligo vulgaris is described as multiple lesions predominantly occurring over the trunk, shoulder, arms and thighs. Lesions occurring over face, neck, hands, feet and legs were termed as Acrofacial vitiligo. Lip-tip vitiligo is a special 
type of vitiligo with lesions over lips and periungual areas Autoimmune and endocrine disorder like thyroid disease,(3) Alopecia areata were recorded as a part of history and clinical examination.

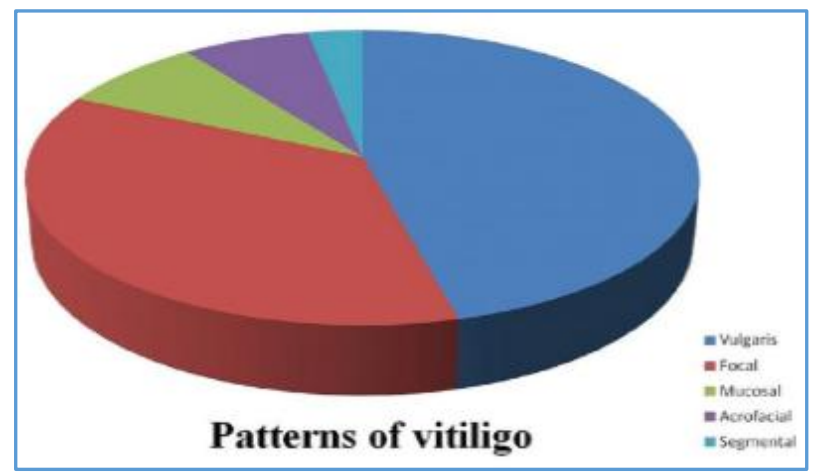

Laboratory parameters like haemogram, peripheral blood smear, blood glucose and thyroid profile were performed in all patients.

Study Design- It is a descriptive study.

Study Setting- Department of DVL, Andhra Medical College, King George Hospital, Visakhapatnam.

\section{RESULTS}

Out of 30 selected patients, 12 were male patients (40\%) and 18 were female patients $(60 \%)$ and female-to-male ratio was $1.5: 1$ that indicates female preponderance. Maximum number of children with $40 \%$ were seen in between the age groups of 10 - 18 years.

\begin{tabular}{|c|c|}
\hline Age Group & $\begin{array}{c}\text { Number of Patients within that Age } \\
\text { Group with Vitiligo }\end{array}$ \\
\hline 0 -5 years & 6 patients \\
\hline 6-10 years & 13 patients \\
\hline 11-18 years & 11 patients \\
\hline \multicolumn{2}{|c|}{ Out of 30 Patients } \\
\hline
\end{tabular}

\begin{tabular}{|c|c|c|}
\hline Age Distribution & Duration of Vitiligo & No. of Patients \\
\hline 0-5 years & $>5$ years & 10 \\
\hline 6-10 years & $1-5$ years & 12 \\
\hline 11-18 years & $>5$ years & 08 \\
\hline \multicolumn{3}{|c|}{ Among 30 Patients } \\
\hline
\end{tabular}

\begin{tabular}{|c|c|}
\hline Type of Vitiligo & Number of Patients (\%) \\
\hline Vitiligo vulgaris & $40 \%$ \\
\hline Focal vitiligo & $20 \%$ \\
\hline Segmental vitiligo & $20 \%$ \\
\hline Acrofacial vitiligo & $10 \%$ \\
\hline \multicolumn{2}{|c|}{ Out of 30 Patients } \\
\hline
\end{tabular}

\begin{tabular}{|c|c|}
\hline Associated Features & Number of Patients \\
\hline Physical trauma & 3 patients \\
\hline Leukotrichia & 6 patients \\
\hline Halo Nevus & 3 patients \\
\hline Koebner's phenomenon & 10 patients \\
\hline Thyroid diseases & 02 patients \\
\hline $\begin{array}{c}\text { Psoriasis and premature } \\
\text { greying of hair }\end{array}$ & 01 patient \\
\hline \multicolumn{2}{|c|}{ Among 30 Patients, List of associated Features } \\
\hline
\end{tabular}

There were no significant association of dietary habits with vitiligo.
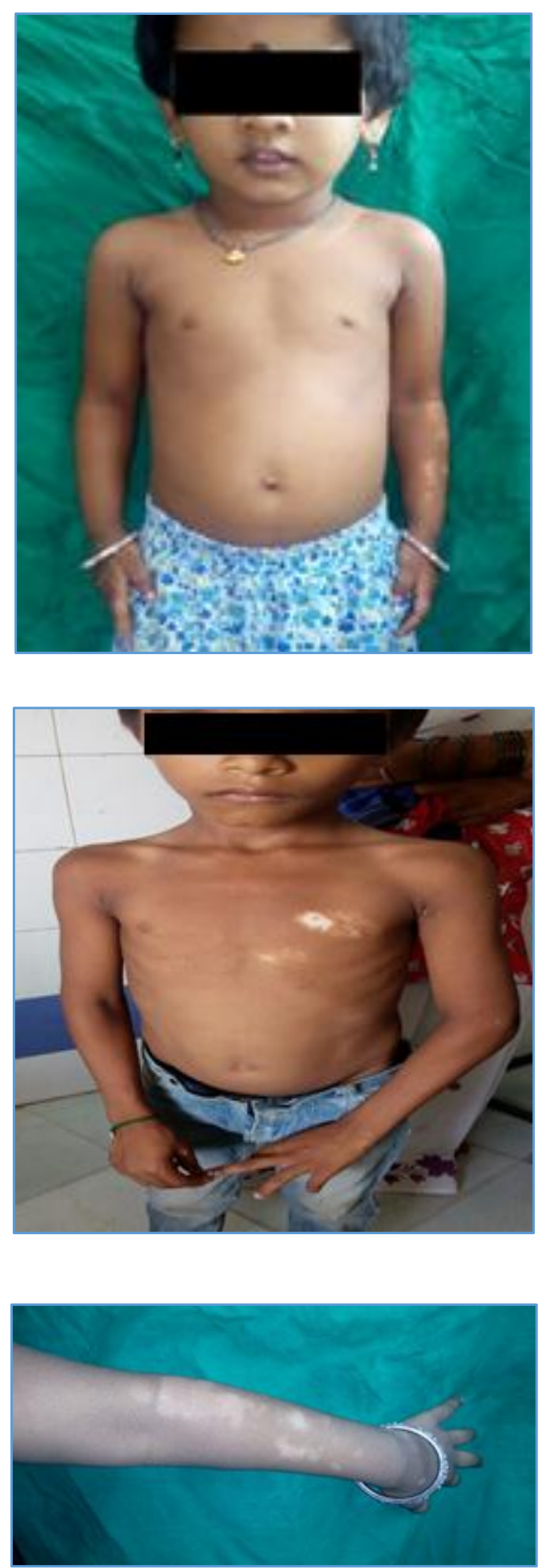


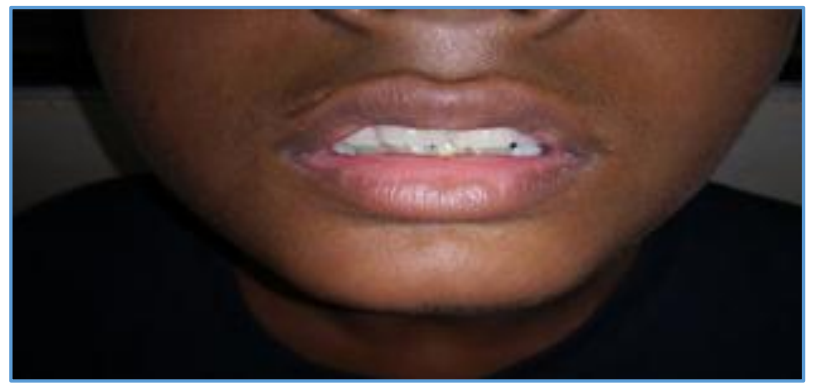

Images showing various Types of Vitiligo in Children

\section{DISCUSSION}

Vitiligo is a common acquired form of depigmentary condition resulting from the progressive loss of melanocytes. It is characterised by milky-white sharply demarcated macules. Vitiligo has in general been classified into two major forms: Segmental vitiligo (typically unilateral maculae in a segmental/ band-shaped distribution) and non-segmental vitiligo (bilateral maculae, often distributed in an acrofacial pattern or scattered symmetrically over the entire body). According to a recent Vitiligo Global Issue Consensus Conference, the term 'vitiligo' can be used as an umbrella term for all non-segmental forms of vitiligo (including several variants: acrofacial, mucosal, generalised, universal, mixed and rare variants of vitiligo). Amongst autoimmune diseases, the strongest association is with thyroid disease.

The association between vitiligo and halo naevi is well established: Several reports have documented the onset of vitiligo at the same time as or shortly after the appearance of a halo naevus, and in a recent study halo naevi were present in $31.1 \%$ of all vitiligo patients. The Koebner phenomenon is a well-known phenomenon in vitiligo (also called isomorphic response). It has been defined as the development of lesions at sites of trauma to uninvolved skin of patients with cutaneous diseases.(4) Both the genetic and epigenetic factors plays an important role in aetiogenesis of acne. An alteration in the micro environment of Epidermal-melanin unit plays an important role in immunological and neurochemical factors.(5,6) Disruption in the process of physiological melanisation causing death and disappearance of melanocytes.

A genetic factor is undoubtedly involved in vitiligo. Inheritance has been suggested to be polygenic. Approximately, $30 \%$ of nearly all of the genes identified at these loci encoded components of the immune system. The exception is TYR, which encodes the enzyme tyrosinase.

\section{These are the Factors that are implicated in the} Aetiopathogenesis of Vitiligo

1. Immune response hypothesis .(7)

2. Neural hypothesis.

3. Autotoxic and self-destructive.

4. Composite hypothesis.

5. Melanocyte growth factor reduction hypothesis.

6. Anti-oxidant deficient theory.

7. Melanocytorrhagy.

8. Apoptosis of vitiligo melanocytes.
In various studies, the prevalence of vitiligo in childhood (age $<12$ years) has been quoted to be around one quarter of vitiligo patients of all ages. In a Chinese study, $24.1 \%$ of the vitiligo patients were in the paediatric age group. Among Korean patients with vitiligo, $16 \%$ were children. In two Indian studies, the prevalence has been reported to be $26 \%$ (south India) and $23.3 \%$ (north India), respectively. The prevalence of SV is higher in children $(17 \%-29 \%)$ as compared to that in adults (5\%).

Among the various ethnic groups, SV is more common in the Korean population. In our study, vitiligo vulgaris is the most common type with $40 \%$ in the children in between the age groups of 6 - 10 years with mean age of onset around 6 years compared to the mean age of onset of 5.6 years and 7.28 years in Korean and Chinese studies, respectively.

\section{CONCLUSION}

In our study, Vitiligo vulgaris was the most common type $(40 \%)$ with female preponderance $(60 \%)$ with mean age of onset at 6 years and showing association with autoimmune diseases, particularly thyroid disorders, psoriasis etc. and with cutaneous diseases like Atopic dermatitis and Halo nevus. Even though it was not a life-threatening disorder, it has psychological impact especially on children. So, in the management of a Childhood Vitiligo, it is very essential to establish a relationship with the child.

\section{REFERENCES}

[1] Bolognia J, Pawelek JM. Biology of hypopigmentation. J Am Acad Dermatol 1988;19(2 Pt 1):217-55.

[2] Ezzedine K, Lim HW, Suzuki T, et al. Revised classification/nomenclature of vitiligo and related issues: the Vitiligo Global Issues Consensus Conference. Pigment Cell Melanoma Res 2012;25(3):E1-13.

[3] Lacovelli P, Sinagra JL, Vidolin AP, et al. Relevance of thyroiditis and of other autoimmune diseases in children with vitiligo. Dermatology 2005;210(1):2630.

[4] van Geel N, Speeckaert R, Taieb A, et al. Koebner's phenomenon in vitiligo: European position paper. Pigment Cell Melanoma Res 2011;24(3):564-73.

[5] Pajvani U, Ahmad N, Wiley A, et al. The relationship between family medical history and childhood vitiligo. J Am Acad Dermatol 2006;55(2):238-44.

[6] Kent G, Al'Abadie M. Psychologic effects of vitiligo: a critical incident analysis. J Am Acad Dermatol 1996;35(6):895-8.

[7] Richmond JM, Frisoli ML, Harris JE. Innate immune mechanisms in vitiligo: danger from within. Curr Opin Immunol 2013;25(6):676-82. 